\title{
Fresh State Properties of Self-compacting Concrete with Recycled Aggregates - A Literature Review
}

\author{
By Sara Almeida Santos* \\ Pedro Raposeiro da Silva \\ Jorge de Brito \\ Luis Evangelista ${ }^{+}$
}

This paper presents a literature review on the Fresh state properties of selfcompacting concrete with fine and coarse recycled aggregates. The growing environmental awareness of today's society causes greater concern with the high consumption of natural resources and the waste originated by the activities of the various industries. In particular, the construction industry consumes a large part of those resources and is, currently, the main responsible for the production of waste in Europe, whose dumping and treatment results in severe environmental and economic consequences. Given that concrete is the most commonly used material in the construction activity, it becomes a significant portion of the construction and demolition waste. In this context, the work developed intends to present a literature review on the incorporation of recycled aggregates $(R A)$ in the production of self-compacting concrete (SCC). For each concrete property, the following information was collected: type and physical characteristics of the materials used for SCC production; mix composition; tests results; discussion and conclusions on those tests. A description of the experimental campaigns performed is first presented. Next, each fresh state property of the SCC is analyzed based on the results obtained by the various authors. The concrete's properties analyzed in the fresh state are: slump-flow diameter and slump flow time, V-funnel time, L-box, J-ring and sieve segregation. The theme of SCC with $R A$ is of great relevance to society since this increasingly requires the construction industry to adopt new processes that minimize the negative impacts on the environment.

Keywords: Contamination, Identity, Mediterranean, Water.

\section{Introduction}

The main difference between SCC, with or without RA, and conventional concrete (CC) is their workability characteristics that allow them to completely fill the moulds, even in densely reinforced elements, with no flocculation, exudation

\footnotetext{
${ }^{*}$ University of Lisbon, Portugal.

* Assistant Professor, CERIS ICIST, Higher Institute of Engineering of Lisbon, Portugal.

${ }^{\dagger}$ Professor, CERIS ICIST, University of Lsibon, Portugal.

${ }^{+}$Associate Professor, University of Stavanger, Norway.
} 
or segregation, solely under their own weight and with no resort to compaction methods (Silva and de Brito, 2015).

In order to comply with the workability requirements of a SCC, the following characteristics must be analyzed: the flow capacity (filling), the passing capacity (fluidity), the viscosity, and the stability (resistance to segregation) (EPG, 2005).

Adjusting the mixing water is an extremely important issue when considering the use of RA. The mortar adhered to the original natural aggregates (NA) has a high porosity thus influencing the RA's water absorption. It is necessary to know the potential absorption and evolution of the absorption over time of the RA in order to estimate the effective water/cement (W/C) ratio during and after mixing. It is thus possible to guarantee the same workability with that of a $\mathrm{CC}$ and ensure a uniform quality of the concrete mass. Ferreira et al. (2011) concluded that slightly worse results of the general performance of concrete are obtained when the RA are pre-saturated before mixing instead of compensating the mixing water. To make the SCC more competitive, it is essential to reduce the raw materials costs. A study on high-performance SCC demonstrates that by reducing the superplasticizers content and replacing a moderate percentage of cement by additions (fly ash (FA)) it is possible to obtain more economical mixes without compromising their properties (Naik et al., 2012).

\section{Literature Review}

This section presents a general description of the experimental campaigns analyzed. In every campaign the authors produced a SCC without RA called reference concrete (RC). This mix was compared with the remaining SCC made with RA (here called RASCC), where usually the replacement ratio of NA with RA varied.

Kou and Poon (2009) studied SCC with fine recycled aggregates (FRA) and coarse recycled aggregate (CRA) incorporation. The study consisted on the production of three RASCC families composed of 100\% CRA and different replacement ratios of river sand with FRA. The characteristics of the aggregates are as follows: fine natural aggregates (FNA) - Natural river sand - with a specific gravity of $2.62, \mathrm{D}_{\max }<5 \mathrm{~mm}$ and water absorption(24h) of $0.88 \%$; FRA with specific gravity of $2.30, \mathrm{D}_{\max }<5 \mathrm{~mm}$ and water absorption(24h) of $11.86 \%$, CRA10 with specific gravity of $2.49, \mathrm{D}_{\max }$ of $10 \mathrm{~mm}$ and water absorption(24h) of $4.26 \%$ and CRA20 with specific gravity of $2.57, \mathrm{D}_{\max }$ of $20 \mathrm{~mm}$ and water absorption(24h) of $3.52 \%$.

The mixes from the $1^{\text {st }}$ and $2^{\text {nd }}$ families were produced with different incorporation percentages of $0,25,50,75$, and 100 The W/C ratio was $0.53\left(1^{\text {st }}\right.$ family) and 0.44 ( $2^{\text {nd }}$ family). The $3^{\text {rd }}$ family was made with $100 \%$ CRA and FRA with W/C ratios of $0.35,0.40$ and 0.44 . The cement content (type I) was kept constant in all the mixes and two types of FA were used: one from class $f$ (designated f-FA and maximum size of $45 \mu \mathrm{m}$, as cement replacement) and another from class $\mathrm{r}$ (designated $\mathrm{r}-\mathrm{FA}$ and minimum size of $45 \mu \mathrm{m}$, as fine 
aggregate and substitute of the viscosity enhancer to control the segregation of the SCC).

Grdic et al. (2010) studied SCC with CRA incorporation. The study consisted on the production of three SCC types with different replacement percentages of coarse natural aggregate (CNA) with CRA: 0, 50 and 100\%. The SCC constituent contents were kept constant in all the mixes, except for the water, with the objective of maintaining the consistency (slump flow values); thus the W/C ratio of the various mixes varied from 0.41 to 0.45 . The CRA were sourced from a concrete bridge (C37/45 strength class) 40 years old. The characteristics of the RA were as follows: $\mathrm{CRA}_{4 / 8}$ with $\mathrm{D}_{\max }$ of $8 \mathrm{~mm}$ and water absorption of $5.88 \%$; $\mathrm{CRA}_{8 / 16}$ with $\mathrm{D}_{\max }$ of $16 \mathrm{~mm}$ and water absorption of $5.08 \%$.

Tuyan et al. (2014) studied SCC with CRA and FRA incorporation. The study consisted on the production of three SCC families with different replacement percentages of calcareous CNA with CRA: 0, 20, 40 and $60 \%$. The W/C ratio was 0.43 ( $1^{\text {st }}$ family), 0.48 ( $2^{\text {nd }}$ family) and 0.53 ( $3^{\text {rd }}$ family). The cement and FA contents were kept constant in all the mixes, as well as the ratio between coarse aggregates (CNA and CRA) and all the inert materials (limestone filler (LF), FNA, CNA and CRA), 0.45. The characteristics of the aggregates are as follows: FNA with specific gravity of $2.61, \mathrm{D}_{\max }$ of $4 \mathrm{~mm}$ and water absorption of $0.67 \%$; CNA with specific gravity of $2.64, \mathrm{D}_{\max }$ of $16 \mathrm{~mm}$ and water absorption of $0.21 \%$; CRA with specific gravity of $2.48, \mathrm{D}_{\max }$ of $16 \mathrm{~mm}$ and water absorption of $4.80 \%$.

Pereira-de-Oliveira et al. (2014) studied SCC with CRA incorporation. The study consisted on the production of four SCC types with different replacement percentages of CNA with CRA: 0, 20, 40 and $60 \%$. The contents of cement (CEM I 42.5R), LF and NA (natural river sand) were kept constant in all the mixes and the contents of CNA, CRA, $\mathrm{S}_{\mathrm{p}}$ and water were adjusted. Two types of natural river sand $\left(82 \% \mathrm{FNA}_{1.2}\right.$ and $18 \%$ of $\left.\mathrm{FNA}_{4.8}\right)$, two types of CNA $\left(68 \%\right.$ of $\mathrm{CNA}_{9.5}$ and $32 \%$ of $\left.\mathrm{CNA}_{19}\right)$ and two types of CRA $\left(90 \%\right.$ of CRA 9.5 and $10 \%$ of $\left.\mathrm{CRA}_{19}\right)$ were used. All aggregates were previously dried. The CRA were sourced from a recycling plant. The characteristics of the aggregates are as follows: FNA $_{1.2}$ with specific gravity of $2.57, \mathrm{D}_{\max }$ of $1.2 \mathrm{~mm}$ and water absorption of $0.30 \%$; FNA $_{4.8}$ with specific gravity of $2.61, \mathrm{D}_{\max }$ of $4.8 \mathrm{~mm}$ and water absorption of $0.40 \%$; CNA $_{9.5}$ with specific gravity of $2.71, \mathrm{D}_{\max }$ of $9.5 \mathrm{~mm}$ and water absorption of $0.15 \% ; \mathrm{CNA}_{19}$ with specific gravity of $2.70, \mathrm{D}_{\max }$ of $19.0 \mathrm{~mm}$ and water absorption of $0.14 \%$; $\mathrm{CRA}_{9.5}$ with specific gravity of $2.51, \mathrm{D}_{\max }$ of $9.5 \mathrm{~mm}$ and water absorption of $4.10 \%$; $\mathrm{CRA}_{19}$ with specific gravity of $2.49, \mathrm{D}_{\max }$ of $19.0 \mathrm{~mm}$ and water absorption of $4.05 \%$.

Modani and Mohitkar (2014) studied SCC with CRA incorporation. The study consisted of the production of six SCC types with different replacement percentages of CNA with CRA: 0, 20, 40, 60, 80 and 100\%. All the SCC constituent contents were kept constant in all the mixes, except for that of $S_{p}$ (with the objective of maintaining the slump flow in all the mixes). The W/C ratio was also maintained constant: 0.53 . Cement and silica fume $\left(\mathrm{SF}_{\mathrm{U}}\right)$ were used. The CRA were sourced from concrete cubes produced in the laboratory and then crushed. The mixes were designed with the objective of reaching a 28-day compressive strength of $30 \mathrm{MPa}$. The characteristics of the aggregates are as 
follows: $\mathrm{FNA}_{1}$ (natural river sand) with a specific gravity of $2.57, \mathrm{D}_{\max }$ of $1.2 \mathrm{~mm}$ and water absorption of $0.30 \% ; \mathrm{FNA}_{2}$ (natural river sand) with specific gravity of 2.60 and water absorption of $0.84 \%$; CNA (crushed basalt) with aspecific gravity of $2.65, \mathrm{D}_{\max }$ of $12 \mathrm{~mm}$ and water absorption of $1.31 \%$; CRA with specific gravity of $2.27, \mathrm{D}_{\max }$ of $12 \mathrm{~mm}$ and water absorption of $5.64 \%$.

Kebailli et al. (2015) studied SCC with CRA incorporation. The study consisted on the production of four SCC types with different replacement percentages of CNA with CRA: 0, 40, 60 and 100\%. All the SCC constituent contents were kept constant in all the mixes, except those of the CNA and CRA. The (effective water) / (cement + LF) ratio was kept constant $(0.37)$ and the cement used was CEM I 52.5R. The CRA were sourced from the demolition of concrete buildings, of an unknown strength class. The concrete elements were jaw crushed in the laboratory. The characteristics of the aggregates are as follows: FNA (natural river sand) with a specific gravity of 2.67, water absorption of $1.5 \%$ and grain size of 0-4 mm; CNA with a specific gravity of 2.67, water absorption of $1.0 \%$, loss of wear of $15 \%$ and grain size of $4-10 \mathrm{~mm}$; CRA with a specific gravity of 2.50 , water absorption of $5.1 \%$, loss of wear of $35 \%$ and grain size of $4-$ $10 \mathrm{~mm}$

Table 1 presents a qualitative summary of the SCC constituents used by the various authors under analysis. It is found that most of the studies focus on the replacement of CNA with CRA. The average W/C ratio of the SCC produced was 0.43 . In every case $S_{p}$ was used. This admixture is fundamental for the concrete fresh-state characteristics on order to be classified as SCC. FA, $\mathrm{SF}_{\mathrm{u}}$ and LF were used in some studies also with the objective of improving the SCC's fresh-state properties.

Table 1. Qualitative Overview of the Materials used in SCC Production

\begin{tabular}{|c|c|c|c|c|c|c|c|c|c|c|c|c|}
\hline \multirow[b]{2}{*}{ Authors } & \multirow[b]{2}{*}{$\mathrm{W} / \mathrm{C}$} & \multirow[b]{2}{*}{$\sum_{\text {II }}$} & \multirow[b]{2}{*}{$\mathbb{I}$} & \multirow[b]{2}{*}{$\frac{L^{-2}}{s}$} & \multirow[b]{2}{*}{ 岑 } & \multirow[b]{2}{*}{ की } & \multirow[b]{2}{*}{$\sum_{>}^{\mathbb{S}}$} & \multicolumn{3}{|c|}{ NA } & \multicolumn{2}{|c|}{ RA } \\
\hline & & & & & & & & $\overleftrightarrow{Z}$ & $\begin{array}{l}* \\
* \\
\mathbb{Z} \\
\text { Z゙ }\end{array}$ & 死 & 艺 & $\frac{\mathbb{x}}{I}$ \\
\hline Kou and Poon, 2009 & $\begin{array}{l}0.53 ; 0.44 ; \\
0.35\end{array}$ & $\sqrt{ }$ & $\sqrt{ }$ & $\times$ & $x$ & $\sqrt{ }$ & $\sqrt{ }$ & $x$ & $\sqrt{ }$ & $x$ & $\sqrt{ }$ & $\sqrt{ } *$ \\
\hline Grdic et al., 2010 & $\begin{array}{l}0.41 ; 0.43 \\
0.45\end{array}$ & $\sqrt{ }$ & $x$ & $\times$ & $\sqrt{ }$ & $\sqrt{ }$ & $x$ & $\sqrt{ }$ & $\sqrt{ }$ & $x$ & $\sqrt{*}$ & $x$ \\
\hline Tuyan et al., 2014 & $\begin{array}{l}0.43 ; 0.48 \\
0.53\end{array}$ & $\sqrt{ }$ & $\sqrt{ }$ & $\times$ & $\sqrt{ }$ & $\sqrt{ }$ & $x$ & $\sqrt{ }$ & $x$ & $\sqrt{ }$ & $\sqrt{ } *$ & $x$ \\
\hline $\begin{array}{l}\text { Pereira-de-Oliveira et al., } \\
2014\end{array}$ & $0.57 ; 0.56$ & $\sqrt{ }$ & $x$ & $\times$ & $\sqrt{ }$ & $\sqrt{ }$ & $x$ & $\sqrt{ }$ & $\sqrt{ }$ & $x$ & $\sqrt{ } *$ & $x$ \\
\hline $\begin{array}{l}\text { Modani and Mohitkar, } \\
2014\end{array}$ & 0.53 & $\sqrt{ }$ & $x$ & $\sqrt{ }$ & $x$ & $\sqrt{ }$ & $x$ & $\sqrt{ }$ & $\sqrt{ }$ & $x$ & $\sqrt{ }$ & $x$ \\
\hline Kebaïli et al., 2015 & 0.37 & $\sqrt{ }$ & $x$ & $\sqrt{ }$ & $\sqrt{ }$ & $\sqrt{ }$ & $x$ & $\sqrt{ }$ & $\sqrt{ }$ & $x$ & $\sqrt{ }$ & $x$ \\
\hline
\end{tabular}




\section{Properties of SCC with RA}

For each property and each author, the results obtained are presented and the trends identified and justified. Finally, a comparison of the property values from the various authors is made.

In the fresh state the following properties are analyzed: fluidity and flow speed in the absence of obstructions, viscosity and filling ability and passing ability through confined spaces.

In the researches consulted the slump flow (which evaluates the fluidity and flow speed in the absence of obstructions), the V-funnel test (which evaluates the viscosity and filling ability) and the L-box test to obtain the passing ability ratio for SCC (which evaluates the passing ability through confined spaces) are the most frequent in fresh-state SCC.

The sieve segregation test (which evaluates the segregation resistance) and the slump flow test with the J-ring (which evaluates the passing ability through confined spaces analogously to the L-box) are not found in most of the studies, essentially because they more recent and therefore insufficiently validated.

\section{Fluidity and Flow Speed in the Absence of Obstructions}

The slump flow test for SCC is made according to EN 12350-8, 2009. The parameters that allow evaluating the fluidity and flow speed in the absence of obstructions are the time that the SCC takes to form a $500 \mathrm{~mm}$ circle, called flow time $\left(\mathrm{T}_{500}\right)$ and the slump flow diameter $(\mathrm{SF})$.

The SF decreases and the $\mathrm{T}_{500}$ increases with the incorporation of CRA. These trends are justified by the greater water absorption of the RA relative to the NA.

Kou and Poon (2009) found that the slump flow increased as the incorporation ratio of FRA grew. That is attributed to the high water absorption capacity of the FRA relative to the river sand. As the FRA content increased, more water was added and therefore the slump flow grew.

On the other hand, Grdic et al. (2010) found that the slump flow decreased as the CRA incorporation ratio increased, since higher ratios means more water is absorbed by the aggregates. In terms of flow time, Grdic et al. (2010) found that it increases with the CRA incorporation ratio (with the exception of the apparently anomalous result for $50 \%$ incorporation). This is due to the CRA being more angular and having a rougher surface that the CNA.

Tuyan et al. (2014) found that the slump flow first increases with the CRA incorporation ratio (20\%). For higher ratios $(40 \%$ and $60 \%$ ), the slump flow decreases. As for the flow time, Tuyan et al. (2014) found that it increases with the CRA incorporation ratio, because of their rougher surface by comparison with the NA and the lower content of $S_{p}$ in the mix. Figure 1 shows that the flow time increases as the $\mathrm{W} / \mathrm{C}$ ratio decreases, as expected. 
Figure 1. Slump Flow Time Test Results (Adpated from Tuyan et al., 2014)

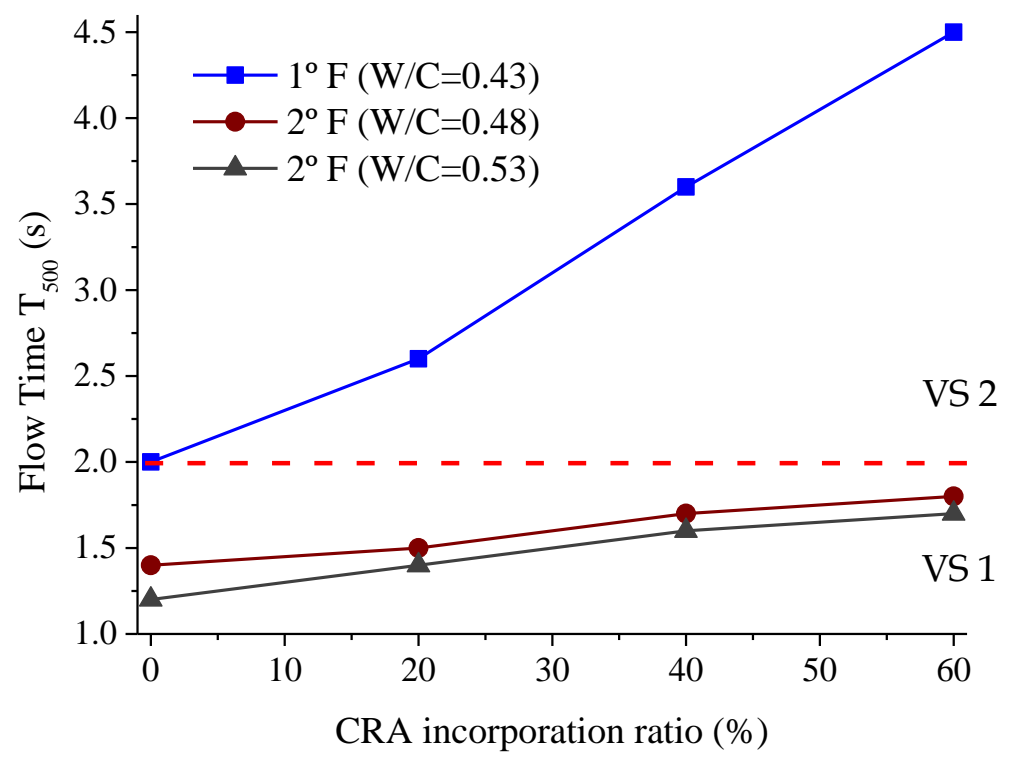

Pereira-de-Oliveira et al. (2014) found that the slump flow increases with the CRA incorporation ratio. This is justified by the gradual increase of the $S_{p}$ content needed, which was caused by the increase of the water absorbed by the CRA as its incorporation ratio grew while simultaneously maintaining the slump flow range established by the authors.

Modani and Mohitkar (2014) obtained slump flow values in the 620-770 mm range. The authors stated that the slump flow increases with CRA incorporation until $60 \%$ (except for an apparently anomalous result for $40 \%$ incorporation), after which it decreases. These trends were also found in the Tuyan et al. (2014) campaigns, and the justification provided was the same. In terms of flow time, it was found that it decreases until $60 \%$ of CRA incorporation (except for an apparently anomalous result for $20 \%$ incorporation), relative to the reference SCC ( $0 \%$ CRA). Above that incorporation level the flow time increases because of the greater absorption of the CRA. This trend was also found in the Safiuddin et al. (2011) campaign.

Kebailli et al. (2015) found that the slump flow decreases as the CRA incorporation ratio increases. For the $60 \%$ and $100 \%$ ratios the requirement from EN 12350-8 (2009) for class SF 2, i.e. that the slump flow is higher than $650 \mathrm{~mm}$, is not fulfilled. In terms of the flow time, it was found that all SCC showed the required flow time except for the one with $100 \%$ CRA. For that mix the flow time was not measured because the slump flow never reached $500 \mathrm{~mm}$.

Figures 2 and 3 show a summary of the slump flow diameter results from the authors under analysis (for various incorporation ratios of RA). 
Figure 2. Slump Flow Time Test Results Overview

$\rightarrow-$ Kou and Poon (2009): W/C $=0.53$ (CRA and FRA)

$\longrightarrow$ Kou and Poon (2009): W/C $=0.44$ ( CRA and FRA )

$\longrightarrow$ Grdic et al. (2010): W/C $=0.41 ; 0.43 ; 0.45$ (CRA)

$\longrightarrow$ Tuyan et al. (2014): $\mathrm{W} / \mathrm{C}=0.43$ (CRA)

$\longrightarrow$ Tuyan et al. (2014): W/C $=0.48$ (CRA)

— Tuyan et al. (2014): $\mathrm{W} / \mathrm{C}=0.53$ (CRA)

$\longrightarrow \smile$ Pereira-de-Oliveira et al. (2014): W/C $=0.57$ (CRA)

$\longrightarrow$ Modani and Mohitkar (2014): W/C $=0.53$ (CRA)

\# Kebaili et al. (2015): W/C=0.38 (CRA)

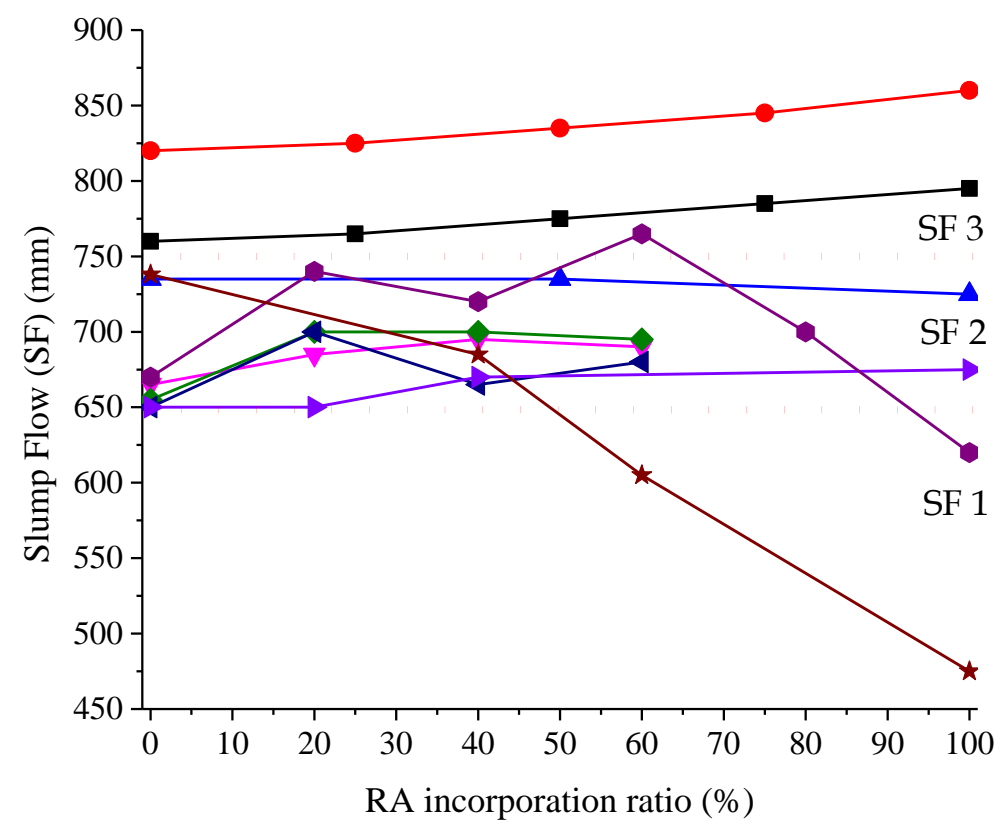

The campaigns of Grdic et al. (2010) and Pereira-de-Oliveira et al. (2014) show that the slump flow decreases with the CRA incorporation ratio, since more water is absorbed by the aggregates as the ratio increases. This trend did not occur in the Kou and Poon (2009) campaign. These authors used FRA, unlike the others. In the Tuyan et al. (2014) and Modani and Mohitkar (2014) campaigns, it was found that the slump flow increases with the CRA incorporation ratio (until $20 \%$ to $60 \%)$.

As the ratio increases (from 50\% to $100 \%$ ), the lump flow decreases because the fine fraction increases partly because the CRA tend to break into smaller particles during mixing. Thus more water is absorbed by the RA and the slump flow tends to decrease. 
Figure 3. $S F_{R A S C C} / S F_{R C}$ Ratio
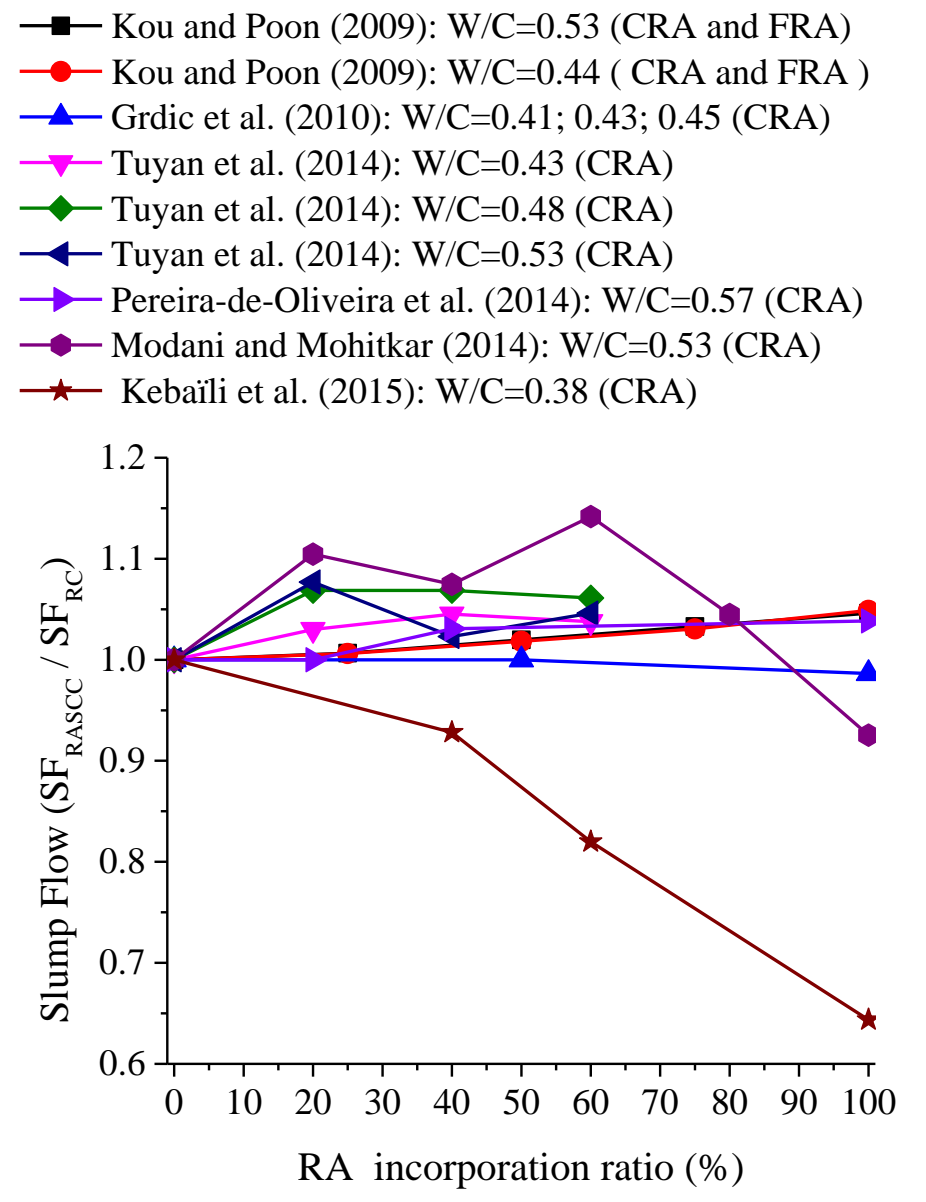

Viscosity and Filling Ability

The V-funnel test is performed according to EN 12350-9, 2009. The parameter that allows evaluating the viscosity and the filling ability and the ability to pass through small openings is the time that concrete tends to flow through the funnel, designated $\mathrm{V}$-funnel flow time $\left(\mathrm{t}_{\mathrm{v}}\right.$, in $\left.\mathrm{s}\right)$.

The V-funnel flow time is found to increase with RA incorporation. This is due to the greater water absorption of the RA relative to the NA.

Tuyan et al. (2014) found that the V-funnel flow time increased with the CRA incorporation ratio. This is explained by their rougher surface relative to the NA and the lower $S_{p}$ contents used. Fig. 4 shows that the V-funnel flow increases as the $\mathrm{W} / \mathrm{C}$ ratio decreases, as expected.

Pereira-de-Oliveira et al. (2014) found that the V-funnel flow time increased for the CRA incorporation ratios of $20 \%$ and $40 \%$. The mix with $40 \%$ CRA had the highest flow time since it is has the lowest $\mathrm{W} / \mathrm{C}$ ratio $(0.56)$. The remaining mixes have the same $\mathrm{W} / \mathrm{C}$ ratio $(0.57)$. Therefore the authors refer that the $\mathrm{V}$ funnel flow time is strongly influenced by the $\mathrm{W} / \mathrm{C}$ ratio. The results obtained by these authors are presented in Figure 4. 
Modani and Mohitkar (2014) found that the V-funnel flow time first decreased with CRA incorporation (at 20\%). Above that ratio it was found that the $\mathrm{V}$-funnel flow time increased (Figure 4).

Figures 4 and 5 present a summary of the V-funnel flow time results obtained by the authors under analysis (for various incorporation ratios of RA).

Figure 4. V-funnel Flow Time Test Results Overview

- Tuyan et al. (2014): W/C $=0.43$ (CRA)

- Tuyan et al. (2014): W/C $=0.48$ (CRA)

$\longrightarrow$ Tuyan et al. (2014): W/C=0.53 (CRA)

$\longrightarrow$ Pereira-de-Oliveira et al. (2014): W/C $=0.57$ (CRA)

$\longleftarrow$ Modani and Mohitkar (2014): W/C $=0.53$ (CRA)

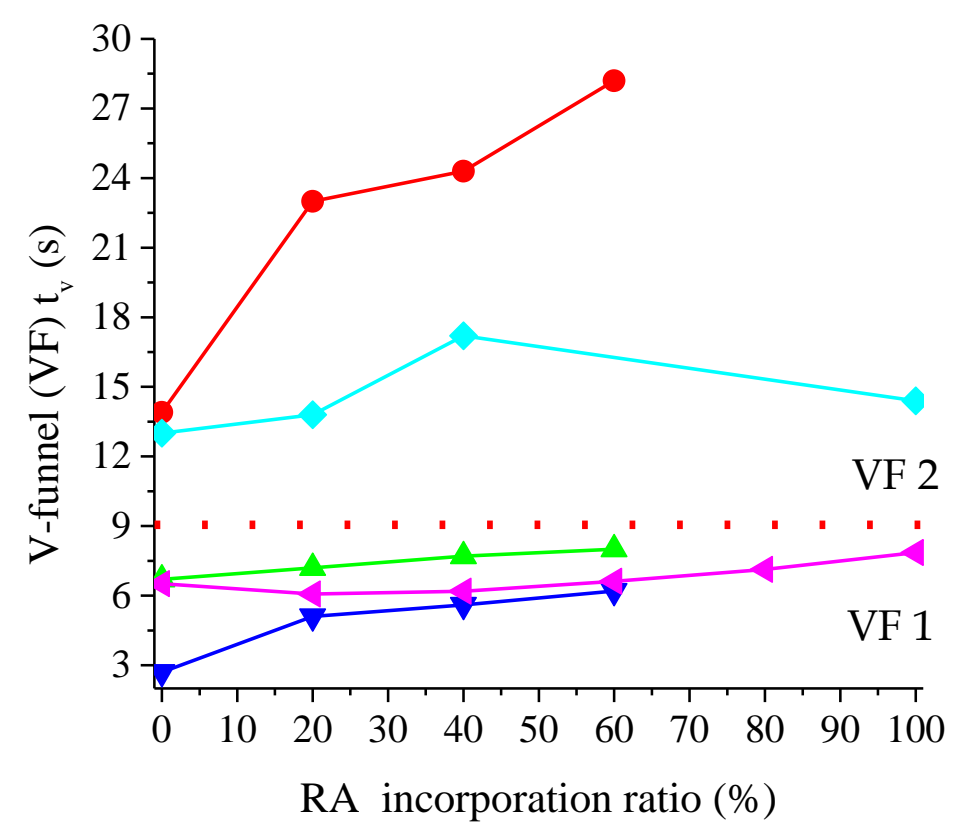

Figure 4 shows that the higher $\mathrm{V}$-funnel flow time values occur for lower $\mathrm{W} / \mathrm{C}$ ratios (as expected). In most studies it is found that the $\mathrm{V}$-funnel flow time is lower in the reference SCC, as expected (Figure 5). Tuyan et al. (2014) found that the V-funnel flow time increases with CRA incorporation ratio due to their rougher surface relative to the NA. Modani and Mohitkar (2014) found that the Vfunnel flow time decreases for relatively small CRA incorporation ratios (until $20 \%$ to $40 \%$ ). For higher ratios, the V-funnel flow time decreases because if the higher rugosity and angularity of the CRA. 
Figure 5. $V F_{R A S C C} / V F_{R C}$ Ratio

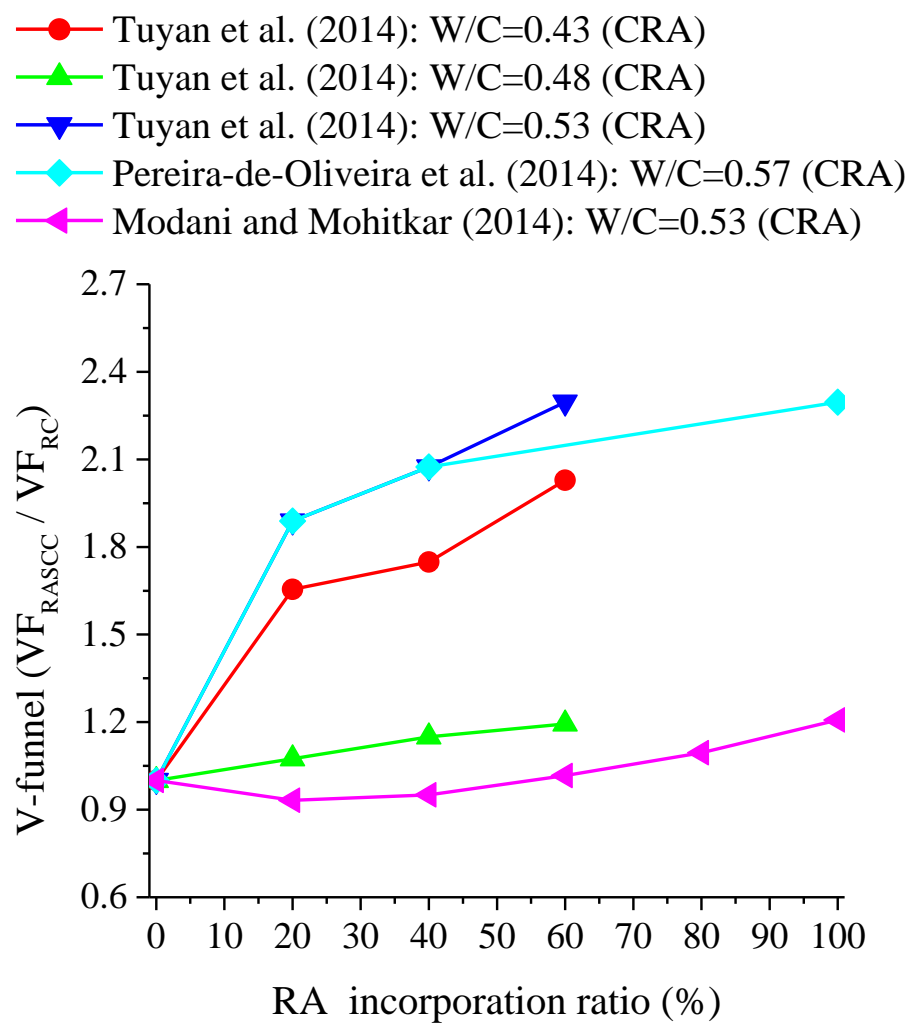

\section{Passing Ability through Confined Spaces}

The L-box test is performed according to EN 12350-10, 2009. The parameter that allows evaluating the passing ability through confined spaces do SCC, including those between reinforcements rebars and other obstructions, without segregating or blocking, is the L-box passing ability index (PL).

It is found that the L-box passing ability index decreases as the CRA incorporation ratio increases (maintaining constant the W/C ratio and the Sp content). This is due to the greater water absorption of the CRA relative to the NA.

All the mixes tested by Kou and Poon (2009) showed a good passing ability through narrow spaces, i.e. the PL values always exceeded 0.80 .

The PL value increased with the FRA incorporation ratio because of the lower water absorption of the FRA in the beginning of the mixing (Figure 6). During that time the FRA did not absorb all its water capacity and therefore the resulting free water contributed to an increase of passing ability (increase if the PL value). Adding FA caused an increase of the slump flow and PL values, since this type of addition allows increasing the fresh-state viscosity (Silva and de Brito, 2015).

In the Grdic et al. (2010) campaign, a good passing ability was registered, with PL values between 0.94 and 0.98, which increase with CRA incorporation (Figure 6). This trend is explained by the increase of the W/C ratio.

Tuyan et al. (2014) found that the passing ability increases as the W/C ratio decreases. For the same W/C ratio the passing ability increases (except for the 
apparently anomalous result for $40 \%$ and $60 \%$ of CRA incorporation in the 3rd family). This is explained by the gradual increase of $S_{p}$ content. Therefore the increase of $S_{p}$ increases the passing ability even when the CRA incorporation ratio also increases. The results obtained by these authors are presented in Figure 6.

Modani and Mohitkar (2014) also obtained the PL values (Figure 6) complying with the limits imposed by EN 206-9. 2010. Figure 6 shows that the mix with 100\% CRA has a lower PL value even though the $S_{p}$ content is greater in this mix.

Figures 6 and 7 present a summary of the L-box passing ability index results obtained by the authors under analysis (for various incorporation ratios of RA).

The PL values tend to increase with the RA incorporation ratio, as seen in the Kou and Poon (2009) and Grdic et al. (2010) campaigns. In the Kou and Poon (2009) campaign, that is justified by the lower water absorption of the FRA in the beginning of the mixing process. On the other hand, Grdic et al. (2010) argue that the reason is the gradual increase of the W/C ratio with the RA incorporation ratio. In every study it is found that the PL value is lower in the reference SCCC, except in the Modani and Mohitkar (2014) campaign where a higher PL value was obtained for $100 \%$ of CRA incorporation, even though the mix had a higher $S_{p}$ content. The PL values increase as the $\mathrm{W} / \mathrm{C}$ ratio decreases (as expected); this trend is more clearly seen in the Tuyan et al. (2014) campaign.

Figure 6. L-Box Test Results Overview
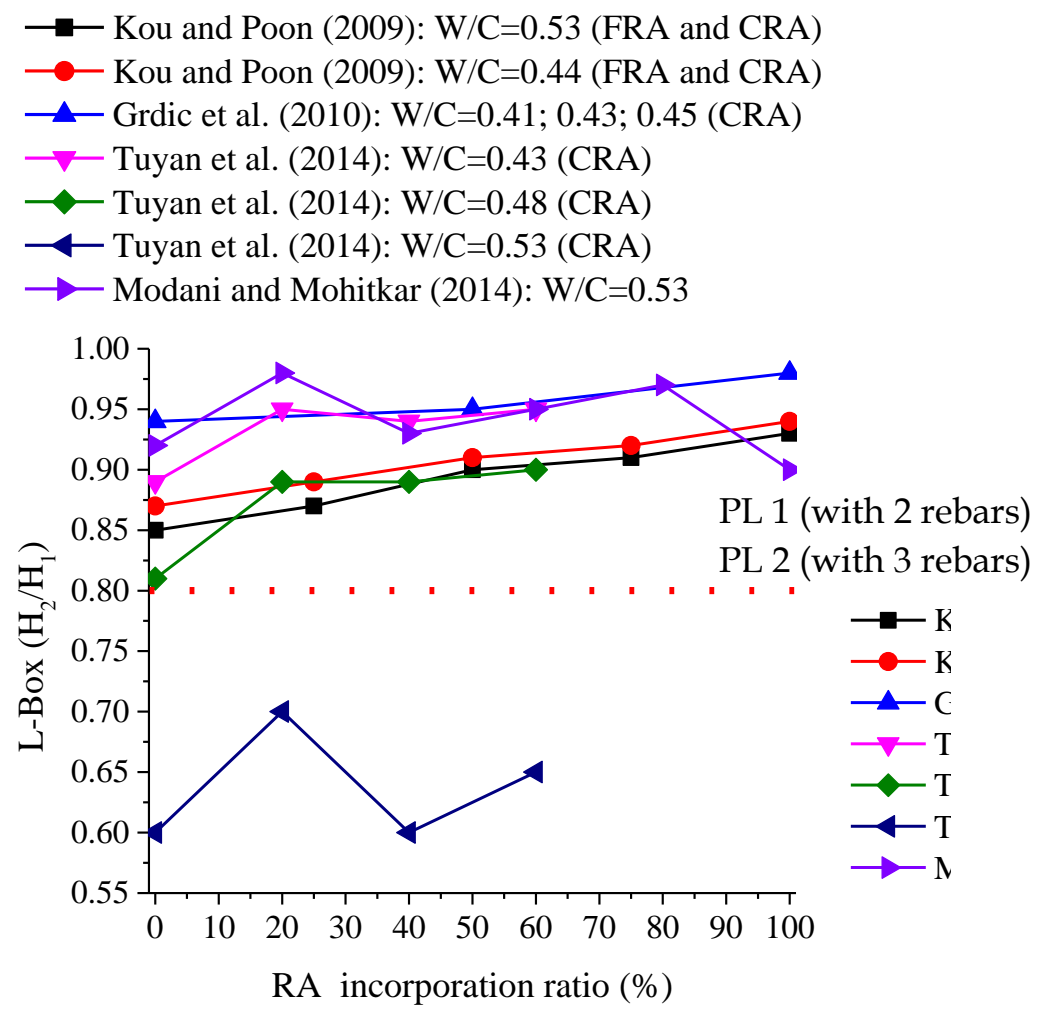
Figure 7. $P L_{R A S C C} / P L_{R C}$ Ratio

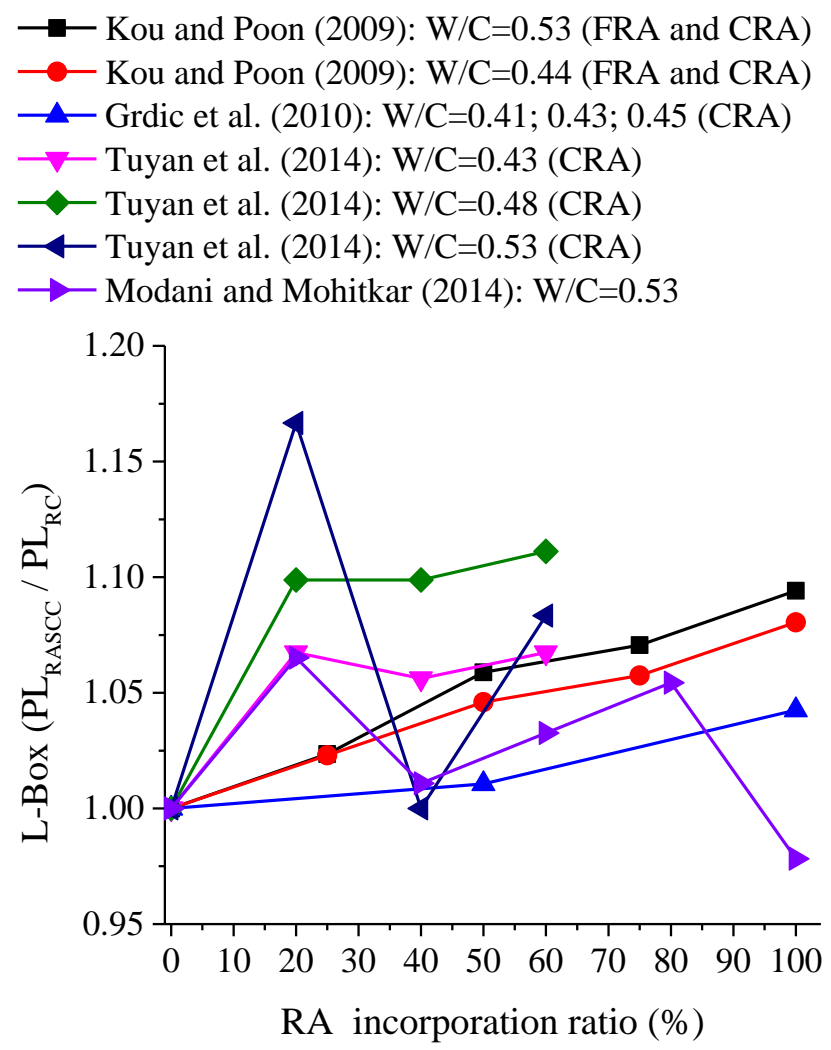

\section{Conclusions}

This literature survey shows that the use of RA in SCC production is viable. Generally it is found that the RA properties are inferior to those of the NA, mostly because of the presence of adhered mortar in the RA. It is thus concluded that this presence is one of the main reasons for the loss of quality of the RA. Consequently, the RA has lower density, greater water absorption and lower mechanical strength than the NA. These properties are the ones that most influence the performance of the SCC in which they are incorporated. However, mostly due to the collection/crushing processes that make the RA more similar to the original NA (less adhered mortar), these performance differences are presently quite acceptable and allow, with some adjustments, the incorporation of these aggregates in concrete production.

It is very important to evaluate the SCC fresh-state properties, since it must have specific characteristics to be considered self-compacting, i.e. it must gave the capacity to flow and compact under its own weight only, fill the moulds with all the reinforcement bars, piping, negatives, etc., maintaining its homogeneity, without the need for any on site vibration means. Table 2 presents a summary of all studies analyzed on the influence of the incorporation of RA (for an incorporation ratio of $100 \%$ ) on the SCC fresh-state properties. 
Table 2. CRA and FRA's Influence on SCC's Fresh-state Performance in Previous Researches

\begin{tabular}{|c|c|c|c|c|}
\hline \multirow{2}{*}{\multicolumn{2}{|c|}{ Fresh-state properties }} & \multicolumn{2}{|l|}{ Replacement } & \multirow{3}{*}{$\begin{array}{l}\text { Studies } \\
\text { CRA - Grdic et al. } \\
\text { (2010); Modani and } \\
\text { Mohitkar (2014). }\end{array}$} \\
\hline & & \multirow{2}{*}{$\begin{array}{l}\text { CRA } \\
(-) \quad 6.7 \quad \% \\
(S=5.0)\end{array}$} & \multirow{2}{*}{ CRA+FRA } & \\
\hline \multirow{3}{*}{$\begin{array}{l}\text { Fluidity and } \\
\text { flow speed in } \\
\text { the absence of } \\
\text { obstructions }\end{array}$} & \multirow[b]{2}{*}{ Slump flow diameter } & & & \\
\hline & & (+) $3.8 \%$ & $\begin{array}{l}(+) 4.7 \% \\
(\mathrm{~S}=0.2)\end{array}$ & $\begin{array}{l}\text { CRA - Pereira-de- } \\
\text { Oliveira et al. (2014). } \\
\text { CRA+FRA - Kou and } \\
\text { Poon (2009). }\end{array}$ \\
\hline & Slump flow time & $\begin{array}{l}\text { (+) } 25.0 \% \\
(\mathrm{~S}=19,1)\end{array}$ & - & $\begin{array}{l}\text { CRA - Grdic et al. } \\
(2010) \text {; Modani and } \\
\text { Mohitkar (2014). }\end{array}$ \\
\hline $\begin{array}{l}\text { Viscosity, } \\
\text { filling ability } \\
\text { and ability to } \\
\text { pass through } \\
\text { small openings }\end{array}$ & V-funnel flow time & $\begin{array}{l}\text { (+) } 62.10 \% \\
(\mathrm{~S}=80.43)\end{array}$ & - & $\begin{array}{l}\text { CRA - Pereira-de- } \\
\text { Oliveira et al. (2014); } \\
\text { Modani and Mohitkar } \\
\text { (2014). }\end{array}$ \\
\hline $\begin{array}{l}\text { Passing ability } \\
\text { through } \\
\text { confined spaces }\end{array}$ & L box index & $\begin{array}{l}(+) \quad 7.6 \quad \% \\
(\mathrm{~S}=2.9)\end{array}$ & $\begin{array}{l}(+) 8.7 \% \\
(\mathrm{~S}=1.0)\end{array}$ & $\begin{array}{l}\text { CRA - Grdic et al. } \\
(2010) \text {. } \\
\text { CRA+FRA - Kou and } \\
\text { Poon (2009). }\end{array}$ \\
\hline
\end{tabular}

It is generally found that, even though there is a loss of performance in the fresh state, the SCC with RA show a satisfactory behavior with no segregation or exudation as reported by these studies. Under these conditions it can be stated that the differences in fresh-state performance can be easily corrected by changing the $S_{\mathrm{p}} / \mathrm{p}_{\%}$ (percentage, in mass, of $S_{p}$ and fine materials in the mix) and $V_{w} / V_{p}$ (ratio, in absolute volume, between the total amount of water and fine materials) ratios of the mixes.

\section{Acknowledgments}

The authors acknowledge the support of Foundation for Science and Technology (FCT) through the funding received regarding the project reference SFRH/ PROTEC/67426/2010. The support of the CERis-ICIST research centre is also acknowledged.

\section{References}

EPG (European Project Group), BIBM, CEMBUREAU, ERMCO, EFCA EFNARC - The European Guidelines for Self Compacting Concrete, Specification - Production and Use (2005), 63.

Ferreira L., de Brito J., Barra M., "Influence of the pre-saturation of recycled coarse concrete aggregates on the fresh and hardened properties of concrete", Magazine of 
Concrete Research, Vol. 63, No. 8 (2011), p. 617-627. http://dx.doi.org/10.1680/macr. 2011.63.8.617.

Grdic, Z. J., Toplicic-Curcic, G. A., Despotovic, I. M., Ristic, N. S., "Properties of selfcompacting concrete prepared with coarse recycled concrete aggregate", Construction and Building Materials, Vol. 24, No. 7 (2010), p. 1129-1133. doi:10.1016/j.conbuil dmat.2009.12.029.

Kebaili, O., Mouret, M., Arabi, N. and Cassagnabere, F., "Adverse effect of the mass substitution of natural aggregates by air-dried recycled concrete aggregates on the selfcompacting ability of concrete: evidence and analysis through an example", Journal of Cleaner Production, Vol. 87 (2015), p. 752-761. doi:10.1016/j.jclepro.2014.10.077.

Kou, S. C., Poon, C. S., "Properties of self-compacting concrete prepared with coarse and fine recycled concrete aggregates", Cement and Concrete Composites, Vol. 31, No. 9 (2009), p. 622-627. doi:10.1016/j.cemconcomp.2009.06.005.

Modani, P. O., Mohitkar, V. M., "Self-compacting concrete with recycled aggregate: A solution for sustainable development", International Journal of Civil and Structural Engineering, Vol. 4, No. 3 (2014), p. 430-440.

Naik, T. R., Kumar, R., Ramme, B. W., Canpolat, F., "Development of high-strength, economical self-consolidating concrete", Construction and Building Materials, Vol. 30 (2012), p. 463-469. doi:10.1016/j.conbuildmat.2011.12.025.

Pereira-de-Oliveira, L. a.; Nepomuceno, M. C. S.; Castro-Gomes, J. P.; Vila, M. F. C., "Permeability properties of self-compacting concrete with coarse recycled aggregates", Construction and Building Materials, Vol. 51 (2014), p. 113-120. doi:10.1016/j.con buildmat.2013.10.061.

Safiuddin, M. D., Salam, M. A., Jumaat, M. Z., "Effects of recycled concrete aggregate on the fresh properties of self-consolidating concrete", Archives of Civil and Mechanical Engineering, Vol. 11, Issue 4 (2011), pp. 1023-1041. doi.org/10.1016/S1644-9665(12) 60093-4.

Silva P. R. and de Brito J. de - Fresh-State Properties of Self-Compacting Mortar and Concrete with Combined Use of Limestone Filler and Fly Ash, Materials Research, vol.18, n.5 (Sep/Oct 2015), p. 1097-1108. http://dx.doi.org/10.1590/1516-1439.028 715.

Tuyan, M., Mardani-Aghabaglou, A., Ramyar, K., "Freeze-thaw resistance, mechanical and transport properties of self-consolidating concrete incorporating coarse recycled concrete aggregate", Materials \& Design, Vol. 53 (2014), p. 983-991. doi:10.1016/ j.matdes.2013.07.100. 